\title{
Effects of the systemic administration of omega-3 polyunsaturated fatty acid on experimental periodontitis
}

\author{
Aveen Ageel Jalal,' Zewar A. AL-Qassab,' and Rafel A. AL-Rawi² \\ 'College of Dentistry, Hawler Medical University, Erbil, Kurdistan Region, Iraq. \\ ${ }^{2}$ College of Pharmacology, Hawler Medical University, Erbil, Kurdistan Region, Iraq. \\ Correspondence to Aveen Ageel Jalal (email: aveenyawar445@gmail.com). \\ (Submitted: 02 April 2019 - Revised version received: 18 April 2019 - Accepted: 19 May 2019 - Published online: 26 Auqust 2019)
}

\begin{abstract}
Objective The present study was aimed to investigate and evaluate the effects of eicosapentaenoic acid (EPA) on ligature induced periodontitis in rats through the biochemical analysis for rat's serum level of CRP, alkaline phosphatase (ALP) and MDA.

Methods Periodontitis was induced for the studied animals by ligation around the upper central incisor. Twenty five animals were used as a control and gavaged by water only, and 100 animals with the induced periodontitis were divided into four equal groups according to the treatment used which was started at time of ligation removal: Water (P/W), scaling/root planing (P/SRP), $60 \mathrm{mg} / \mathrm{kg}$ EPA (P/EPA), and SRP together with EPA (P/SRP + EPA). Blood was taken by cardiac puncture, after 3, 24 h, 3 days, 1 week and 2 weeks for biochemical analysis.

Results The P/SRP + EPA treatment group showed significant decrease $(p<0.05)$ in serum CRP, significant increase in serum ALP, significant decrease in serum MDA after 1 week, 3 days, and $3 \mathrm{~h}$ respectively in comparison with the P/W treatment group.

Conclusion The treatment by SRP with $60 \mathrm{mg} / \mathrm{kg}$ EPA is better than each one alone and can be used for treatment of periodontitis.

Keywords periodontitis, eicosapentaenoic acid, alveolar bone resorption, omega-3
\end{abstract}

\section{Introduction}

Chronic periodontitis is an inflammatory disease affecting the supporting tissues of teeth, and its expression results from the interaction of host defense mechanisms, microbial agents, environmental, and genetic factors. ${ }^{1}$ A biomarker is a substance used to indicate a biologic state and is an objective measure to evaluate the disease activity and considered as an indicator of normal biologic processes, pathogenic processes, or pharmacologic responses to a therapeutic intervention. ${ }^{2}$ Several biomarkers are associated with periodontal disease like the systemic inflammatory marker such as CRP, bone markers such as alkaline phosphatase (ALP), and oxidative stress markers such as MDA. ${ }^{3-5}$

Ide et al. ${ }^{6}$ found that CRP has been associated with the presence of various bacterial infections, including periodontitis. Perumal et al. ${ }^{5}$ found that there was a decrease in serum bone-specific ALP level in severe periodontitis patients as compared with moderate chronic periodontitis group level. Other study found that patients with periodontitis had higher values of MDA whereas healthy patients had lower levels of MDA which is commonly known as a marker of oxidative stress. $^{7}$

Polyunsaturated fatty acids are fatty acids with more than one carbon-carbon double bond. Omega- 3 are the bioactive lipids which consist of three major omega-3 fatty acids, eicosapentaenoic acid (EPA) and docosahexaenoic acid (DHA) from marine sources, and alpha-linolenic acid (ALA) which is from plant sources. ${ }^{8}$ Periodontal disease affects almost $90 \%$ of the population, ${ }^{9}$ and the incidence increase with the growing ageing population. ${ }^{10,11}$ The most common periodontal treatment is still mechanical removal of plaque and calculus deposit and local antibiotic application. Thus, a therapy of natural origin, if effective, might be safer method for treatment of periodontitis. For this reason, the present study was aimed to investigate and evaluate the effects of $60 \mathrm{mg} / \mathrm{kg} \mathrm{EPA}^{12}$ on ligature-induced periodontitis in rats through the biochemical analysis for serum CRP, ALP, and MDA.

\section{Materials and Methods Rats and Housing}

All the Wister-albino rats used in the study was aged about 8-10 weeks, weighing 200-300 g and cared in the animal house of College of Medicine, Hawler Medical University, Erbil, Iraq. They were allowed to adapt to the housing conditions for 1 week prior to the commencement of the study. Five rats were housed in each wire cage and maintained on a 12-h light/dark cycle at $20 \pm{ }^{\circ} 5 \mathrm{C}$ and $20-30 \%$ humidity. The animals were kept in standard room conditions and fed with a standard rat chow and allowed to drink water ad libitum. The research project was approved by the Research Ethics Committee at College of Dentistry, Hawler Medical University under protocol.

\section{Induction of Experimental Periodontitis}

The upper incisor was chosen because the induced periodontal disease occurs more rapidly in that location due to the porosity of the spongy bone in the maxilla. The rats were anesthetized by intraperitoneal administration of ketamine $(0.5 \mathrm{ml} / \mathrm{kg} \mathrm{b.w.)}$ and the animals were placed on a proper operating table, which allowed open-mouth maintenance of the rats to facilitate access to the teeth. After that a 3.0 sterile black braided silk threads was placed around the cervix of maxillary right incisor for each animal and kept for 2 weeks. The ligatures are knotted on the labial side of the tooth, resulting in subgingival positioning on the palatal side and supragingival position on the labial side. Daily we perform ligatures control and checking, and if any had been lost or become loose, it was replaced. This ligature acts as a gingival irritant for 14 days and promoted the accumulation of plaque and subsequently development of periodontal disease. ${ }^{13}$

\section{Experimental Design for Biochemical Analysis}

One hundred and twenty five animals were used in the study. Twenty five animals (normal control), and 100 animals with the induced periodontitis were randomly assigned into four 
experimental groups (25 animals each) according to the treatment used.

\section{NC/W}

Normal control + distilled water treatment group.

\section{$P / W$}

Ligature-induced periodontitis + distilled water treatment group.

\section{P/SRP}

Ligature-induced periodontitis + scaling and root planing treatment group.

The right incisors were subjected to SRP with manual \#1-2 mini-five curettes through 10 distal-mesial traction movements in the labial and palatal aspects. The interproximal areas were scaled with the same curettes using cervico-incisal traction movements. ${ }^{14}$

\section{P/EPA}

Ligature-induced periodontitis $+60 \mathrm{mg} / \mathrm{kg}$ EPA treatment group.

\section{$P / S R P+E P A$}

Ligature-induced periodontitis + SRP + EPA treatment group.

The ligatures were removed at day 14 (day 0 ) and the different types of treatment was started directly. The treatment by intragastric gavage of distilled water or EPA were done daily once for 2 weeks.

\section{Blood Sampling for Biochemical Assays}

Blood was taken by cardiac puncture, $3 \mathrm{~h}$ after ligation removal (day 0), 24 h, 3 days, 1 week and 2 weeks for immunological analysis. First by anesthetizing the rat, placed on its back, the left index finger was placed at the level of the lowest ribs without applying any pressure, and the heart is located $1 \mathrm{~cm}$ above this point, slightly to the right. ${ }^{15}$ The $5 \mathrm{ml}$ syringe was hold at a $45^{\circ}$ angle and the needle was inserted between two ribs, the plunger was pulled on slowly to fill the syringe. Then the samples were placed in non-heparinized tubes, allowed to clot for $2 \mathrm{~h}$ at room temperature and centrifuged at $3000 \mathrm{rpm}$ for $10 \mathrm{~min}$ at $4^{\circ} \mathrm{C}$, and then the supernatant was collected. The serum was frozen at $-20^{\circ} \mathrm{C}$ and used within 1 month to avoid loss of bioactivity and contamination.

Chemiluminescence immunoassay detection kit was used for determination of high sensitivity CRP (23961, Diagnostic
Automation Inc., Calabasas, CA, USA), colorimetric determination was used of the ALP (02160, Biolabo, France), and enzyme-linked immunosorbent assay kit was used for MDA determination (MBS764641, USA).

\section{Statistical Analysis}

Data were analyzed using SPSS software version 23, and were summarized using means and standard deviations. Statistical analysis with one-way analysis of variance was performed to compare the differences in the means among groups, and when it revealed that there was a statistically significant difference; Mann-Whitney $U$-test was performed to assess individual pair of groups for statistically significant finding. $p$-Value $\leq 0.05$ was considered statistically significant.

\section{Results}

\section{Serum CRP}

The result showed a significant increase $(p<0.05)$ in serum $\mathrm{CRP}$ in $\mathrm{P} / \mathrm{W}, \mathrm{P} / \mathrm{SRP}, \mathrm{P} / \mathrm{EPA}$, and $\mathrm{P} / \mathrm{SRP}+\mathrm{EPA}$ treatment groups in the first 3 days in comparison with the NC/W treatment group. The P/EPA and P/SRP + EPA treatment groups showed a non-significant difference in serum CRP level from that of the NC/W after 7 days treatment, but not lower level to that of the healthy control group. The P/SRP treatment group showed a non-significant difference from that of NC/W treatment group after 2 weeks (Table 1 ).

Statistical analysis showed non-significant differences ( $p$ $>0.05$ ) in serum CRP present between all treatment groups in the first 3 days. After 1 week the P/SRP + EPA treatment group showed significant decrease $(p<0.05)$ in serum CRP in comparison with the $\mathrm{P} / \mathrm{W}, \mathrm{P} / \mathrm{SRP}$, and $\mathrm{P} / \mathrm{EPA}$ treatment groups. After 2 weeks a non-significant differences $(p>0.05)$ were seen between P/SRP and P/EPA, P/SRP and P/SRP + EPA, P/ $\mathrm{EPA}$ and P/SRP + EPA treatment groups (Table 2).

\section{Serum ALP}

The P/W treatment group showed a significant decrease $(p<$ $0.05)$ in serum ALP in comparison with the NC/W. Statistical analysis showed a non-significant differences $(p>0.05)$ present between $\mathrm{P} / \mathrm{EPA}$ and $\mathrm{P} / \mathrm{SRP}+\mathrm{EPA}$ treatment groups in relation with the NC/W treatment groups only after 1 week treatment, but it was still less than the NC/W treatment group. A significant difference $(p<0.05)$ was seen between all groups in all other durations studied (Table 3).

Table 1. Serum CRP (mean \pm standard deviation) in normal control/water treatment group in relation with all studied groups

\begin{tabular}{|c|c|c|c|c|c|c|c|c|c|c|}
\hline \multirow{2}{*}{ Groups } & \multicolumn{9}{|c|}{ CRP (ng/ml) } & \multirow[b]{2}{*}{$p$-Value } \\
\hline & $3 h$ & $p$-Value & $24 h$ & $p$-Value & 3 days & $p$-Value & 1 Week & $p$-Value & 2 Weeks & \\
\hline NCM & $11.81 \pm 1.186$ & 0.012 & $11.61 \pm 1.328$ & 0.012 & $11.41 \pm 1.104$ & 0.012 & $11.61 \pm 1.843$ & 0.012 & $11.81 \pm 1.177$ & 0.012 \\
\hline$P / W$ & $14.61 \pm 0.354$ & & $14.81 \pm 1.18$ & & $14.56 \pm 1.876$ & & $13.954 \pm 1.45$ & & $13.093 \pm 0.963$ & \\
\hline NCM & $11.81 \pm 1.186$ & 0.012 & $11.61 \pm 1.32$ & 0.012 & $11.41 \pm 1.104$ & 0.012 & $11.61 \pm 1.843$ & 0.012 & $11.81 \pm 1.177$ & 0.731 \\
\hline $\mathrm{P} / \mathrm{SRP}$ & $15.22 \pm 0.357$ & & $15.32 \pm 0.451$ & & $15.06 \pm 1.96$ & & $13.569 \pm 1.540$ & & $12.03 \pm 0.75$ & \\
\hline NCM & $11.81 \pm 1.186$ & 0.012 & $11.61 \pm 1.328$ & 0.012 & $11.41 \pm 1.104$ & 0.012 & $11.61 \pm 1.843$ & 0.144 & $11.81 \pm 1.177$ & 0.756 \\
\hline P/EPA & $14.45 \pm 0.344$ & & $14.075 \pm 0.256$ & & $13.99 \pm 1.83$ & & $12.94 \pm 1.275$ & & $12.312 \pm 0.785$ & \\
\hline NCM & $11.81 \pm 1.186$ & 0.012 & $11.61 \pm 1.328$ & 0.012 & $11.41 \pm 1.104$ & 0.012 & $11.61 \pm 1.843$ & 0.173 & $11.81 \pm 1.177$ & 0.347 \\
\hline$P / S R P+E P A$ & $14.057 \pm 1.467$ & & $14.99 \pm 1.985$ & & $13.89 \pm 0.34$ & & $12.01 \pm 0.834$ & & $12.01 \pm 1.157$ & \\
\hline
\end{tabular}




\begin{tabular}{|c|c|c|c|c|c|c|c|c|c|c|}
\hline \multirow{2}{*}{ Groups } & \multicolumn{10}{|c|}{ CRP (ng/ml) } \\
\hline & $3 h$ & $p$-Value & $24 \mathrm{~h}$ & $p$-Value & 3 days & $p$-Value & 1 Week & $p$-Value & 2 Weeks & $p$-Value \\
\hline P/W & $14.61 \pm 0.354$ & 0.92 & $14.81 \pm 1.1815$ & 0.731 & $14.56 \pm 1.876$ & 0.920 & $13.954 \pm 1.45$ & 0.833 & $13.093 \pm 0.963$ & 0.012 \\
\hline P/SRP & $15.22 \pm 0.357$ & & $15.32 \pm 0.451$ & & $15.06 \pm 1.96$ & & $13.569 \pm 1.540$ & & $12.03 \pm 0.75$ & \\
\hline P/W & $14.61 \pm 0.354$ & 1.00 & $14.81 \pm 1.18$ & 0.400 & $14.56 \pm 1.876$ & 0.828 & $13.954 \pm 1.45$ & 0.250 & $13.093 \pm 0.9631$ & 0.012 \\
\hline P/EPA & $14.45 \pm 0.344$ & & $14.075 \pm 0.256$ & & $13.99 \pm 1.83$ & & $12.94 \pm 1.275$ & & $12.312 \pm 0.785$ & \\
\hline$P / W$ & $14.61 \pm 0.354$ & 1.00 & $14.81 \pm 1.18$ & 0.417 & $14.56 \pm 1.876$ & 0.528 & $13.954 \pm 1.45$ & 0.012 & $13.093 \pm 0.963$ & 0.012 \\
\hline$P / S R P+E P A$ & $14.057 \pm 1.467$ & & $14.99 \pm 1.985$ & & $13.89 \pm 0.34$ & & $12.01 \pm 0.834$ & & $12.01 \pm 1.157$ & \\
\hline P/SRP & $15.22 \pm 0.35711$ & 0.828 & $15.32 \pm 0.451$ & 0.920 & $15.06 \pm 1.96$ & 0.674 & $13.569 \pm 1.540$ & 0.144 & $12.03 \pm 0.75$ & 0.920 \\
\hline P/EPA & $14.45 \pm 0.34$ & & $14.075 \pm 0.256$ & & $13.99 \pm 1.83$ & & $12.94 \pm 1.275$ & & $12.312 \pm 0.785$ & \\
\hline P/SRP & $15.22 \pm 0.357$ & 0.400 & $15.32 \pm 0.451$ & 1.00 & $15.06 \pm 1.96$ & 0.313 & $13.569 \pm 1.540$ & 0.012 & $12.03 \pm 0.75$ & 1.00 \\
\hline$P / S R P+E P A$ & $14.057 \pm 1.467$ & & $14.99 \pm 1.985$ & & $13.89 \pm 0.34$ & & $12.01 \pm 0.834$ & & $12.01 \pm 1.157$ & \\
\hline P/EPA & $14.45 \pm 0.344$ & 1.00 & $14.075 \pm 0.256$ & 0.920 & $13.99 \pm 1.83$ & 1.00 & $12.94 \pm 1.275$ & 0.012 & $12.312 \pm 0.785$ & 1.00 \\
\hline$P / S R A+E P A$ & $14.057 \pm 1.467$ & & $14.99 \pm 1.985$ & & $13.89 \pm 0.34$ & & $12.01 \pm 0.834$ & & $12.01 \pm 1.157$ & \\
\hline
\end{tabular}

Table 3. Serum ALP (mean \pm standard deviation) in normal control/water treatment group in relation with all studied groups

\begin{tabular}{|c|c|c|c|c|c|c|c|c|c|c|}
\hline \multirow{2}{*}{ Groups } & \multicolumn{10}{|c|}{$A L P(U / L)$} \\
\hline & $3 h$ & $p$-Value & $24 \mathrm{~h}$ & $p$-Value & 3 days & $p$-Value & 1 Week & $p$-Value & 2 Weeks & $p$-Value \\
\hline NCM & $131.07 \pm 2.595$ & 0.012 & $131.27 \pm 2.72$ & 0.012 & $129.87 \pm 3.476$ & 0.012 & $131.47 \pm 4.193$ & 0.012 & $132.27 \pm 4.543$ & 0.021 \\
\hline$P / W$ & $114 \pm 4.149$ & & $114.87 \pm 3.827$ & & $116.076 \pm 4.027$ & & $116.9 \pm 0.761$ & & $117.5 \pm 1.014$ & \\
\hline $\mathrm{NCM}$ & $131.07 \pm 2.595$ & 0.012 & $131.27 \pm 2.72$ & 0.008 & $129.87 \pm 3.476$ & 0.012 & $131.47 \pm 4.193$ & 0.012 & $132.27 \pm 4.543$ & 0.012 \\
\hline P/SRP & $114.47 \pm 4.009$ & & $113.73 \pm 1.896$ & & $115.476 \pm 3.26$ & & $114.4 \pm 2.80$ & & $118.276 \pm 4.246$ & \\
\hline $\mathrm{NCM}$ & $131.07 \pm 2.595$ & 0.012 & $131.27 \pm 2.72$ & 0.012 & $129.87 \pm 3.476$ & 0.012 & $131.47 \pm 4.193$ & 0.060 & $132.27 \pm 4.543$ & 0.094 \\
\hline P/EPA & $115.876 \pm 4.19$ & & $116.45 \pm 2.34$ & & $120.7 \pm 1.256$ & & $123.9 \pm 2.546$ & & $124.5 \pm 1.526$ & \\
\hline$N C M$ & $131.07 \pm 2.595$ & 0.012 & $131.27 \pm 2.72$ & 0.021 & $129.87 \pm 3.476$ & 0.021 & $131.47 \pm 4.193$ & 0.060 & $132.27 \pm 4.543$ & 0.060 \\
\hline$P / S R P+E P A$ & $118.5 \pm 4.402$ & & $120.3 \pm 3.389$ & & $122.7 \pm 1.526$ & & $124.1 \pm 1.797$ & & $124.9 \pm 1.968$ & \\
\hline
\end{tabular}

The P/EPA and P/SRP + EPA treatment groups showed significant increase $(p<0.05)$ in serum ALP after 3 days in comparison with the $\mathrm{P} / \mathrm{W}$ treatment group. The $\mathrm{P} / \mathrm{EPA}$ and $\mathrm{P} /$ $\mathrm{SRP}+\mathrm{EPA}$ treatment groups showed significant increase $(p<$ 0.05 ) in serum ALP after 3 days treatment in comparison with the P/SRP treatment group. The P/SRP + EPA treatment group showed a significant difference from P/EPA treatment group after 3 and 24 h only (Table 4 ).

\section{Serum MDA}

Statistical analysis showed that all types of treatment for periodontitis (water, SRP, EPA, or by SRP + EPA) showed significant increase $(p<0.05)$ in serum MDA in relation with the NC/W treatment group (Table 5).

Statistical analysis showed that the treatment by SRP, EPA, SRP + EPA caused significant decrease $(p<0.05)$ in serum $\mathrm{MDA}$ in comparison with the $\mathrm{P} / \mathrm{W}$ treatment group in all durations studied. No significant differences $(p>0.05)$ were seen between P/SRP and P/EPA, P/SRP and P/SRP + EPA, or $\mathrm{P} / \mathrm{EPA}$ and $\mathrm{P} / \mathrm{SRP}+\mathrm{EPA}$ treatment groups in all durations studied (Table 6).

\section{Discussion}

\section{Serum CRP}

CRP is an acute phase protein, synthesized by the liver and circulates in the blood and rise in response to inflammation and used as an inflammatory marker. ${ }^{6}$ The present study showed that $\mathrm{P} / \mathrm{W}$ treatment group showed significant increase in level of serum CRP. Ekuni et al. ${ }^{16}$ found that the serum CRP in normal rats was $1.22 \mathrm{mg} / \mathrm{ml}$, while in the periodontitis group showed a significantly $12 \%$ increase compared with that of the control group at time of suture removal. Buhlin et al., ${ }^{17}$ Craig et al., ${ }^{18}$ Thakare et al., ${ }^{19}$ Gupta et al., ${ }^{20}$ Masi et al., ${ }^{21}$ Aziz et al.,22 and Monisha and Savitha ${ }^{7}$ also found that the levels of CRP were significantly higher in periodontitis patients than healthy control. The balance between ROS and antioxidant defense mechanism is important in the pathogenesis of periodontal disease, and those subjects who were infected with periodontal pathogens had clearly higher levels of CRP than those who were not harboring the putative bacteria in their subgingival plaque. These results disagree with that of Buduneli et al. ${ }^{23}$ result, they induced experimental periodontitis in rats by 


\begin{tabular}{|c|c|c|c|c|c|c|c|c|c|c|}
\hline \multirow{2}{*}{ Groups } & \multicolumn{10}{|c|}{$\operatorname{ALP}(U / L)$} \\
\hline & $3 h$ & $p$-Value & $24 \mathrm{~h}$ & $p$-Value & 3 days & $p$-Value & 1 Week & $p$-Value & 2 Weeks & $p$-Value \\
\hline P/W & $114 \pm 4.149$ & 0.920 & $114.87 \pm 3.827$ & 0.857 & $116.076 \pm 4.027$ & 0.833 & $116.9 \pm 0.761$ & 0.173 & $117.5 \pm 1.014$ & 0.674 \\
\hline P/SRP & $114.47 \pm 4.009$ & & $113.73 \pm 1.896$ & & $115.476 \pm 3.260$ & & $114.4 \pm 2.80$ & & $118.276 \pm 4.246$ & \\
\hline P/W & $114 \pm 4.149$ & 0.920 & $114.87 \pm 3.827$ & 0.603 & $116.076 \pm 4.027$ & 0.0463 & $116.9 \pm 0.761$ & 0.012 & $117.5 \pm 1.014$ & 0.012 \\
\hline P/EPA & $115.876 \pm 4.19$ & & $116.45 \pm 2.34$ & & $120.7 \pm 1.256$ & & $123.9 \pm 2.546$ & & $124.5 \pm 1.526$ & \\
\hline$P / W$ & $114 \pm 4.149$ & 0.144 & $114.87 \pm 3.827$ & 0.116 & $116.076 \pm 4.027$ & 0.0164 & $116.9 \pm 0.761$ & 0.012 & $117.5 \pm 1.014$ & 0.012 \\
\hline$P / S R P+E P A$ & $118.5 \pm 4.402$ & & $120.3 \pm 3.389$ & & $122.7 \pm 1.526$ & & $124.1 \pm 1.797$ & & $124.9 \pm 1.968$ & \\
\hline P/SRP & $114.47 \pm 4.009$ & 0.756 & $113.73 \pm 1.896$ & 0.412 & $115.476 \pm 3.260$ & 0.036 & $114.4 \pm 2.80$ & 0.012 & $118.276 \pm 4.246$ & 0.021 \\
\hline P/EPA & $115.876 \pm 4.19$ & & $116.45 \pm 2.34$ & & $120.7 \pm 1.256$ & & $123.9 \pm 2.546$ & & $124.5 \pm 1.526$ & \\
\hline P/SRP & $114.47 \pm 4.009$ & 0.144 & $113.73 \pm 1.896$ & 0.083 & $115.476 \pm 3.260$ & 0.012 & $114.4 \pm 2.80$ & 0.012 & $118.276 \pm 4.246$ & 0.036 \\
\hline$P / S R P+E P A$ & $118.5 \pm 4.402$ & & $120.3 \pm 3.389$ & & $122.7 \pm 1.526$ & & $124.1 \pm 1.797$ & & $124.9 \pm 1.968$ & \\
\hline P/EPA & $115.876 \pm 4.19$ & 0.014 & $116.45 \pm 2.34$ & 0.034 & $120.7 \pm 1.256$ & 0.057 & $123.9 \pm 2.546$ & 0.527 & $124.5 \pm 1.526 \backslash$ & 1.00 \\
\hline$P / S R P+E P A$ & $118.5 \pm 4.402$ & & $120.3 \pm 3.389$ & & $122.7 \pm 1.526$ & & $124.1 \pm 1.797$ & & $124.9 \pm 1.968$ & \\
\hline
\end{tabular}

\begin{tabular}{|c|c|c|c|c|c|c|c|c|c|c|}
\hline \multirow{2}{*}{ Groups } & \multicolumn{10}{|c|}{ MDA (ng/ml) } \\
\hline & $3 \mathrm{~h}$ & $p$-Value & $24 \mathrm{~h}$ & $p$-Value & 3 days & $p$-Value & One Week & $p$-Value & Two Weeks & $p$-Value \\
\hline NC/W & $22.12 \pm 0.920$ & 0.012 & $21.9 \pm 0.663$ & 0.012 & $22.3 \pm 1.204$ & 0.012 & $22.5 \pm 0.707$ & 0.012 & $22.4 \pm 0.894$ & 0.012 \\
\hline P/W & $32.8 \pm 1.303$ & & $32.4 \pm 1.516$ & & $31.6 \pm 1.14$ & & $31.2 \pm 1.303$ & & $30.6 \pm 0.894$ & \\
\hline NCM & $22.12 \pm 0.920$ & 0.012 & $21.9 \pm 0.663$ & 0.012 & $22.3 \pm 1.204$ & 0.012 & $22.5 \pm 0.707$ & 0.012 & $22.4 \pm 0.894$ & 0.012 \\
\hline P/SRP & $27.54 \pm 1.143$ & & $26.34 \pm 1.275$ & & $26.94 \pm 1.190$ & & $26.74 \pm 1.26$ & & $26.34 \pm 1.768$ & \\
\hline NC/W & $22.12 \pm 0.920$ & 0.012 & $21.9 \pm 0.663$ & 0.012 & $22.3 \pm 1.204$ & 0.012 & $22.5 \pm 0.707$ & 0.012 & $22.4 \pm 0.894$ & 0.028 \\
\hline P/EPA & $26.44 \pm 1.43$ & & $26.54 \pm 1.28$ & & $26.34 \pm 1.275$ & & $26.14 \pm 1.41$ & & $25.74 \pm 0.859$ & \\
\hline NCM & $22.12 \pm 0.920$ & 0.012 & $21.9 \pm 0.663$ & 0.012 & $22.3 \pm 1.204$ & 0.012 & $22.5 \pm 0.707$ & 0.028 & $22.4 \pm 0.894$ & 0.028 \\
\hline $\mathrm{P} / \mathrm{SRP}+\mathrm{EPA}$ & $26.5 \pm 1.903$ & & $25.94 \pm 1.663$ & & $25.64 \pm 1.273$ & & $25.34 \pm 1.08$ & & $25.14 \pm 1.431$ & \\
\hline
\end{tabular}

\begin{tabular}{|c|c|c|c|c|c|c|c|c|c|c|}
\hline \multirow{2}{*}{ Groups } & \multicolumn{10}{|c|}{ MDA (ng/ml) } \\
\hline & $3 \mathrm{~h}$ & $p$-Value & $24 \mathrm{~h}$ & $p$-Value & 3 days & $p$-Value & 1 Week & $p$-Value & 2 Weeks & $p$-Value \\
\hline$P / W$ & $32.8 \pm 1.303$ & 0.012 & $32.4 \pm 1.516$ & 0.012 & $31.6 \pm 1.14$ & 0.012 & $31.2 \pm 1.303$ & 0.012 & $30.6 \pm 0.894$ & 0.012 \\
\hline P/SRP & $27.54 \pm 1.143$ & & $26.34 \pm 1.275$ & & $26.94 \pm 1.190$ & & $26.74 \pm 1.26$ & & $26.34 \pm 1.768$ & \\
\hline$P / W$ & $32.8 \pm 1.303$ & 0.012 & $32.4 \pm 1.516$ & 0.012 & $31.6 \pm 1.14$ & 0.012 & $31.2 \pm 1.303$ & 0.012 & $30.6 \pm 0.894$ & 0.012 \\
\hline P/EPA & $26.44 \pm 1.43$ & & $26.54 \pm 1.28$ & & $26.34 \pm 1.275$ & & $26.14 \pm 1.41$ & & $25.74 \pm 0.859$ & \\
\hline $\mathrm{P} / \mathrm{W}$ & $32.8 \pm 1.303$ & 0.012 & $32.4 \pm 1.516$ & 0.012 & $31.6 \pm 1.14$ & 0.012 & $31.2 \pm 1.303$ & 0.012 & $30.6 \pm 0.894$ & 0.012 \\
\hline$P / S R P+E P A$ & $26.5 \pm 1.903$ & & $25.94 \pm 1.663$ & & $26.34 \pm 1.275$ & & $25.34 \pm 1.08$ & & $25.14 \pm 1.431$ & \\
\hline P/SRP & $27.54 \pm 1.143$ & 0.920 & $26.34 \pm 1.275$ & 0.920 & $26.94 \pm 1.190$ & 0.920 & $26.74 \pm 1.26$ & 0.920 & $26.34 \pm 1.768$ & 0.347 \\
\hline P/EPA & $26.44 \pm 1.43$ & & $26.54 \pm 1.28$ & & $26.34 \pm 1.275$ & & $26.14 \pm 1.41$ & & $25.74 \pm 0.859$ & \\
\hline P/SRP & $27.54 \pm 1.143$ & 0.920 & $26.34 \pm 1.275$ & 0.674 & $26.94 \pm 1.190$ & 0.920 & $26.74 \pm 1.26$ & 0.920 & $26.34 \pm 1.768$ & 0.250 \\
\hline$P / S R P+E P A$ & $26.5 \pm 1.903$ & & $25.94 \pm 1.663$ & & $26.34 \pm 1.275$ & & $25.34 \pm 1.08$ & & $25.14 \pm 1.431$ & \\
\hline P/EPA & $26.44 \pm 1.43$ & 0.400 & $26.54 \pm 1.28$ & 0.603 & $26.34 \pm 1.275$ & 0.920 & $26.14 \pm 1.41$ & 0.920 & $25.54 \pm 0.841$ & 1.00 \\
\hline$P / S R P+E P A$ & $26.50 \pm 1.903$ & & $25.94 \pm 1.663$ & & $26.34 \pm 1.275$ & & $25.34 \pm 1.08$ & & $25.74 \pm 0.859$ & \\
\hline
\end{tabular}


repeated injection of purified lipopolysaccharide (LPS) derived from Escherichia coli endotoxin and found no significant differences present between any of the studied groups in serum CRP.

The present study also showed significant increase in serum CRP in P/SRP treatment group in comparison with the $\mathrm{NC} / \mathrm{W}$, but this increase was not significant in relation with the and $\mathrm{P} / \mathrm{W}$ treatment group. The present result agrees with that of Ide et al.'s ${ }^{6}$ study, they found no statistically significant changes in levels of any of CRP after SRP. Tonetti et al. ${ }^{24}$ was found that within $24 \mathrm{~h}$ after periodontal treatment, there were significant increase in CRP indicating an acute systemic inflammatory response, and by day 7 , the periodontal treatment group has equal or lower circulating inflammatory biomarkers than the control group. The increase within $24 \mathrm{~h}$ following periodontal therapy may be a result of intense transient bacteremia and soft tissue damage resulting from periodontal instrumentation. These two results disagree with that of Mattila et $\mathrm{al}^{25}$; they reported a reduction of CRP concentrations on 30 patients with chronic periodontitis after non-surgical periodontal treatment. Miyajima et al. ${ }^{26}$ found that the serum CRP concentrations were not different between the control and the periodontitis rats (control; $10.960 .6 \mathrm{ng} / \mathrm{ml}$ periodontitis; $11.060 .3 \mathrm{ng} / \mathrm{ml}$ ).

The present study also showed that after 1 week the P/SRP + EPA treatment group showed significant decrease $(p<0.05)$ in serum CRP in comparison with the $\mathrm{P} / \mathrm{W}, \mathrm{P} / \mathrm{SRP}$, and $\mathrm{P} / \mathrm{EPA}$ treatment groups. This means that the treatment by EPA with SRP is better than each one alone. Phillips et al. ${ }^{27}$ also found that omega-3 supplementation reduces inflammation as measured by decreased levels of CRP as a marker of inflammation. Naqvi et al. ${ }^{28}$ found that EPA was associated with lower CRP in linear secondary analyses. This may be due to its anti-inflammatory effects. ${ }^{29}$ Serhan and Savill ${ }^{30}$ have been found that omega- 3 in animal models of periodontitis can be a substrates for neutrophil production of resolvins and protectins, which appear central to the resolution of inflammation. Other animal studies have suggested omega- 3 may have a protective effect on periodontitis by decreasing the host inflammatory responses to common microbial pathogens such as Porphyromonas gingivalis and this result in less tissue breakdown. ${ }^{31}$ Vardar-Şengül ${ }^{32}$ study disagree with the present study, they found that omega- 3 cannot be used for treatment of experimental periodontitis induced by repeated injections of $E$. coli LPS in rats, and omega- 3 fatty acid administration did not seem to influence the circulating levels of CRP. This may be due to different methods used.

\section{Serum ALP}

Alkaline phosphatase is a metalloenzyme anchored to the cell membrane, and it is distributed particularly in the liver, bowel, placenta and bone and its activity and function can be modulated by environmental conditions. ${ }^{33}$ The present study showed that the ligature-induced periodontitis caused a significant decrease in ALP serum levels. Kose et al. ${ }^{34}$ found that the normal serum ALP in rats was $124.86 \pm 12.40 \mathrm{U} / \mathrm{L}$, while in periodontitis group was $98.86 \pm 9.40 \mathrm{U} / \mathrm{L}$ after 28 days from ligation removal. Cetinkaya et al. ${ }^{35}$ found that the serum alkaline phosphatase levels were $903.90 \pm 6.76 \mathrm{U} / \mathrm{L}$ in normal control group and $811.0 \pm 6.56 \mathrm{U} / \mathrm{L}$ in experimental periodontitis group after 2 months ligation around the mandibular first molar. Arabac1 et al. ${ }^{36}$ also found the same results. The significant reduction in ALP levels indicates that osteoblastic activity decreased in the periodontal area. Contrary to these results, the measurements of periodontal destruction (probing depth, gingival bleeding, and suppuration) are related to higher levels of ALP in saliva. ${ }^{37}$

The present study also showed that the P/SRP showed no significant difference from that of the $\mathrm{P} / \mathrm{W}$ treatment group regarding the ALP serum levels. Singh et al..$^{38}$ also found that the changes in the level of ALP in serum after SRP was not statistically significant in the study groups with gingivitis, aggressive periodontitis and chronic periodontitis patients. This may be probably due to the fact that the local changes in periodontium may not have a direct effect on the levels of this enzyme in serum. The changing concentration in serum depends on function of other organ systems such as bone, kidney, liver etc. ${ }^{39}$

The P/EPA and P/SRP + EPA treatment groups showed a significant increase $(p<0.05)$ in serum ALP after 3 days in comparison with the $\mathrm{P} / \mathrm{W}$ treatment group. The statistically significant elevation in ALP levels provided by EPA treatment in rats with periodontitis suggests that this therapeutic agent have a significant effect on osteoblasts in periodontitis tissues. Appleton et al. ${ }^{40}$ found that omega- 3 can inhibit the production of inflammatory cytokines such as IL-1, IL- 6 , and TNF- $\alpha$, which provide an important stimulus for osteoclastic bone resorption, and thus may inhibit bone resorption and prevent bone loss. Other study found that supplementation of the diets of growing rats with omega- 3 fatty acids results in greater bone formation in rats, and also they found an increase in ALP activity in osteoblastic cells in culture. ${ }^{41} \mathrm{Al}-\mathrm{H}$ ashemi et al..$^{42}$ found that the total alkaline phosphatase in rat's serum was significantly elevated after treatment with 400 and $600 \mathrm{mg} / \mathrm{kg}$ of omega-3 compared with other studied group. Attia et al. ${ }^{43}$ found that rats fed with 20 $\mathrm{mg} / \mathrm{kg}$ b.w. showed significant increase in serum ALP. Abdou et al. ${ }^{44}$ also found the same increase in rat's serum ALP.

\section{Serum MDA}

Periodontal disease is one of the most common chronic inflammatory diseases, and high oxidative stress might have important roles in the etiopathogenesis of periodontitis. ${ }^{45}$ The present results showed significantly higher levels of serum $\mathrm{MDA}$ in rats in the $\mathrm{P} / \mathrm{W}$ treatment group compared with the NC/W treatment group. Celec et al., ${ }^{46}$ Panjamurthy et al., ${ }^{47}$ Aziz et al.,22 Trivedi et al. ${ }^{48}$ and Ahmadi-Motamaye et al. ${ }^{49}$ also found that serum MDA level was significantly higher in the periodontitis group. Based on the results of these studies, periodontitis can induce systemic oxidative stresses and alter serum MDA levels, and synthesis of MDA might be due to a decrease in antioxidant in destroyed in periodontal tissues.

The present study also showed that treatment by SRP can significantly decrease serum MDA in comparison with the P/W treatment group. Several studies found that successful periodontal therapy increased total antioxidant capacity levels ${ }^{50}$ and decreased MDA levels, ${ }^{50}$ therefore, periodontal therapy can be very useful for the patient.

\section{Conclusion}

The treatment of periodontitis by SRP with the EPA is better than each one alone.

\section{Conflict of Interest}

None. 


\section{References}

1. Offenbacher S, Barros SP, Singer RE, Moss K, Williams RC, Beck JD. Periodontal disease at the biofilm-gingival interface. J Periodontol. 2007;78:1911-1925.

2. Strimbu K, Tavel JA. What are biomarkers? Curr Opin HIV AIDS 2010;5:463466.

3. Jayaprakash D, Aghanashini S, Chatterjee A, Bharwani A, Vijayendra RR, Rosh RM. Effect of periodontal therapy on C-reactive protein levels in gingival crevicular fluid of patients with gingivitis and chronic periodontitis: a clinical and biochemical study. J Indian Soc Periodontol. 2014;18: 456-460.

4. Liu Z, Liu Y, Song Y, Zhang X, Wang S, Wang Z. Systemic oxidative stress biomarkers in chronic periodontitis: a meta-analysis. Dis Markers. 2014:2014:931083.

5. Perumal GCL, Mythili R, Kumar S, Suyambukesan S. Serum total alkaline phosphatase enzyme level and severity of chronic periodontitis. Int J Curr Res Rev. 2014:6:41-44.

6. Ide M, McPartlin D, Coward PY, Crook M, Lumb P, Wilson RF. Effect of treatment of chronic periodontitis on levels of serum markers of acute-phase inflammatory and vascular responses. J Clin Periodontol. 2003;30:334-340.

7. Monisha K, Savitha G. Assessment of oxidative stress in periodontitis patients. J Pharm Sci Res. 2016;8:620-622.

8. Harris WS. Fish oil supplementation: evidence for health benefits. Cleve Clin J Med. 2004;71:208-210.

9. Pihlstrom BL, Tabak L. The National Institute of Dental and Craniofacial Research: research for the practicing dentist. J Am Dent Assoc 2005;136:728-737.

10. Jepsen S, Blanco J, Buchalla W, Carvalho JC, Dietrich T, Dörfer C, et al. Prevention and control of dental caries and periodontal diseases at individual and population level: consensus report of group 3 of joint EFP/ ORCA workshop on the boundaries between caries and periodontal diseases. J Clin Periodontol. 2017;44:S85-S93.

11. Tonetti MS, Bottenberg P, Conrads G, Eickholz P, Heasman P, Huysmans MC, et al. Dental caries and periodontal diseases in the ageing population: call to action to protect and enhance oral health and well-being as an essential component of healthy ageing - Consensus report of group 4 of the joint EFP/ORCA workshop on the boundaries between caries and periodontal diseases. J Clin Periodontol. 2017;44:S135-S144.

12. Araghizadeh N, Paknejad M, Alaeddini M, Minaii B, Abdollahi M, Khorasanie R. The efficacy and prophylactic characteristics of omega-3 fatty acids in experimental gingivitis in rats. Iran J Basic Med Sci. 2014;17:87-92.

13. Ionel A, Lucaciu O, Moga M, Buhatel D, Ilea A, Flaviu T. Periodontal disease induced in Wistar rats - experimental study. Hum Vet Med. 2015;7:90-95

14. Garcia VG, Knoll LR, Longo M, Novaes VC, Assem NZ, Ervolino E, et al. Effect of the probiotic Saccharomyces cerevisiae on ligature-induced periodontitis in rats. J Periodont Res. 2016;51:26-37.

15. Parasuraman $S$, Raveendran R, Kesavan R. Blood sample collection in small laboratory animals. J Pharmacol Pharmacother. 2010;1:87-93.

16. Ekuni D, Tomofuji T, Irie K, Kasuyama K, Umakoshi M, Azuma T, et al. Effects of periodontitis on aortic insulin resistance in an obese rat model. Lab Invest. 2010:90:348-359.

17. Buhlin K, Gustafsson A, Pockley AG, Frostegård J, Klinge B. Risk factors for cardiovascular disease in patients with periodontitis. Eur Heart J. 2003;24:2099-2107.

18. Craig RG, Yip JK, So MK, Boylan RJ, Socransky SS, Haffajee AD. Relationship of destructive periodontal disease to the acute-phase response. J Periodontol. 2003;74:1007-1016.

19. Thakare KS, Deo V, Bhongade ML. Evaluation of CRP serum levels in periodontitis patients with or without atherosclerosis. Indian J Dent Res. 2010;21:326-329.

20. Gupta SC, Jindal V, Ranbika T. CRP and its role in periodontitis. Indian J Dent Sci. 2011;3:31-32.

21. Masi S, Salpea KD, Li K, Parkar M, Nibali L, Donos N, et al. Oxidative stress, chronic inflammation and telomere length in patients with periodontitis. Free Radic Biol Med. 2011;50:730-735.

22. Aziz AS, Kalekar MG, Benjamin T, Suryakar AN, Milsee Mol JP. Chronic periodontitis and oxidative stress - a biochemical study. Indian J Dent Sci. 2012;4:22-26.

23. Buduneli N, Baylas H, Buduneli E, Türkoğlu O, Köse T, Dahlen G. Periodontal infections and pre-term low birth weight: a case-control study. J Clin Periodontol. 2005;32:174-181.
24. Tonetti MS, D'Aiuto F, Nibali L, Donald A, Storry C, Parkar M, et al. Treatment of periodontitis and endothelial function. N Engl J Med. 2007;356:911-920.

25. Mattila K, Vesanen M, Valtonen V, Nieminen M, Palosuo T, Rasi V, et al. Effect of treating periodontitis on C-reactive protein levels: a pilot study. BMC Infect Dis. 2002;2:30

26. Miyajima S, Naruse K, Kobayashi Y, Nakamura N, Nishikawa T, Adachi $K$ et al . Periodontitis-activated monocytes/macrophages cause aortic inflammation. Sci Rep. 2014;4:5171.

27. Phillips T, Childs AC, Dreon DM, Phinney S, Leeuwenburgh C. A dietary supplement attenuates IL-6 and CRP after eccentric exercise in untrained males. Med Sci Sports Exerc 2003;35:2032-2037.

28. Naqvi AZ, Buettner C, Phillips RS, Davis RB, Mukamal KJ. Omega 3 fatty acids and periodontitis in U.S. adults. J Am Diet Assoc 2010;110:1669-1675.

29. Marion-Letellier R, Butler M, Déchelotte P, Playford RJ, Ghosh S. Comparison of cytokine modulation by natural peroxisome proliferator-activated receptor gamma ligands with synthetic ligands in intestinal-like Caco-2 cells and human dendritic cells--potential for dietary modulation of peroxisome proliferator-activated receptor gamma in intestinal inflammation. Am J Clin Nutr. 2008:87:939-948.

30. Serhan CN, Savill J. Resolution of inflammation: the beginning programs the end. Nat Immunol. 2005;6:1191-1197.

31. Hasturk H, Kantarci A, Goguet-Surmenian E, Blackwood A, Andry C, Serhan CN et al. Resolvin E1 regulates inflammation at the cellular and tissue level and restores tissue homeostasis in vivo. J Immunol. 2007;179:7021-7029.

32. Vardar- Şengül S, Buduneli N, Buduneli E, Kardeşler L, Baylas H, Atilla G, et al. Dietary supplementation of omega-3 fatty acid and circulating levels of interleukin-1beta, osteocalcin, and C-reactive protein in rats. J Periodontol. 2006;77:814-820.

33. Whyte MP. Physiological role of alkaline phosphatase explored in hypophosphatasia. Ann N Y Acad Sci. 2010;1192:190-200.

34. Kose O, Arabaci T, Yemenoglu H, Kara A, Ozkanlar S, Kayis S, et al. Influences of fucoxanthin on alveolar bone resorption in induced periodontitis in rat molars. Mar Drugs. 2016;14:1-11.

35. Cetinkaya BO, Acikcoz G, Keles GC, Ayas B, Korkmaz A. The effect of cyclosporin $A$ on alveolar bone in rats subjected to experimental periodontal disease. Toxicol Pathol. 2006;34:716-722.

36. Arabac T, Kermen E,Özkanlar S, Köse O, Kara A, Kızıldağ A, et al. Therapeutic effects of melatonin on alveolar bone resorption after experimental periodontitis in rats: a biochemical and immunohistochemical study. J Periodontol. 2015:86:874-881.

37. Kinney JS, Ramseier CA, Giannobile WV. Oral fluid-based biomarkers of alveolar bone loss in periodontitis. Ann N Y Acad Sci. 2007;1098:230-251.

38. Singh N, Chandel S, Singh H, Agrawal A, Savitha AN. Effect of scaling and root planing on the activity of ALP in GCF \& serum of patients with gingivitis, chronic and aggressive periodontitis: a comparative study. J Oral Biol Craniofac Res. 2017;7:123-126.

39. Weiss MJ, Rosy K, Henthorn PS. Structure of the human liver/bone/kidney alkaline phosphatase activity. J Periodontal Res. 1996;31:66-72.

40. Appleto KM, Fraser WD, Rogers PJ, Ness AR, Tobias JH. Supplementation with a low-moderate dose of $n-3$ long-chain PUFA has no short-term effect on bone resorptionin human adults. Br J Nutr. 2011;105; 1145-1149.

41. Watkins BA, Li Y, Lippman HE, Feng S. Modulatory effect of omega-3 polyunsaturated fatty acids on osteoblast functions and bone metabolism. Prostaglandins Leukot Essent Fatty Acids 2003;68:387-398.

42. Al-Hashemi HM, Al-Khashab EM, Hamdoon AA. Effect of high doses of omega-3 fatty acids on the metabolism of bones in adult females rats. Raf J Sci. 2013;24:17-26.

43. Attia AM, El-Banna SG, Nomeir FR, Abd El-Basser MI. Lindane-induced biochemical perturbations in rat serum and attenuation by omega-3 and Nigella sativa seed oil. Indian J Biochem Biophys 2011;48:184-190.

44. Abdou HM, Hassan MA. Protective role of omega-3 polyunsaturated fatty acid against lead acetate-induced toxicity in liver and kidney of female rats. Med Res Int. 2014;2014:435857.

45. Tóthová L, Kamodyová N, Červenka T, Celec P. Salivary markers of oxidative stress in oral diseases. Front Cell Infect Microbiol. 2015;5:73-79.

46. Celec P, Hodosy J, Celecová V, Vodrázka J, Cervenka T, Halcák L et al.. Salivary thiobarbituric acid reacting substances and malondialdehyde--their relationship to reported smoking and to parodontal status described by the papillary bleeding index. Dis Markers, 2005;21:133-137. 
47. Panjamurthy K, Manoharan S, Ramachandran CR. Lipid peroxidation and antioxidant status in patients with periodontitis. Cell Mol Biol Lett. 2005;10:255-264.

48. Trivedi S, Lal N, Mahdi AA, Singh B, PandeyS. Association of salivary lipid peroxidation levels, antioxidant enzymes, and chronic periodontitis. Int J Periodontics Restorative Dent. 2015;35:e14-e19.
Effects of the systemic administration of omega-3 polyunsaturated

49. Ahmadi-Motamaye F, Goodarzi MT, Jamshidi Z, Kebriaei R. Evaluation of salivary and serum antioxidant and oxidative stress statuses in patients with chronic periodontitis: A Case-Control Study. Front Physiol. 2017:8:189.

50. Guentsch A, Preshaw PM, Bremer-Streck S, Klinger G, Glockmann E, Sigusch, BW. Lipid peroxidation and antioxidant activity in saliva of periodontitis patients: effect of smoking and periodontal treatment. Clin Oral Investig. 2008;12:345-352.

This work is licensed under a Creative Commons Attribution-NonCommercial 3.0 Unported License which allows users to read, copy, distribute and make derivative works for non-commercial purposes from the material, as long as the author of the original work is cited properly. 